\section{Digital hemispherical photography for estimating forest canopy properties: current controversies and opportunities}

\author{
Francesco Chianucci ${ }^{(1-2)}$, Andrea Cutini ${ }^{(1)}$
}

\begin{abstract}
Hemispherical photography has been used since the 1960s in forest ecology. Nevertheless, specific constraints related to film cameras have progressively prevented widespread adoption of this photographic method. Advances in digital photographic technology hold great promise to overcome the major drawbacks of hemispherical photography, particularly regarding field techniques and image processing aspects. This contribution is aimed to: (i) provide a basic foreground of digital hemispherical photography; (ii) illustrate the major strengths and weakness of the method; (iii) provide an reliable protocol for image acquisition and analysis, to get the most out of using hemispherical photography for canopy properties extraction.
\end{abstract}

Keywords: Digital Hemispherical Photography, Fisheye Lens, Leaf Area Index, Radiative Transfer, Foliage Clumping

\section{Introduction}

Accurate and reliable measures of forest canopy are crucial to a wide range of studies including hydrology, carbon and nutrient cycling, and global change (Chen et al. 1997, Macfarlane et al. 2007c). For this reason, forest canopy properties are widely used in many long-term research programs and, on the other hand, to monitoring forest ecosystems' status (Cutini 2003, Macfarlane 2011). In addition, the availability of observations on forest canopy properties such as leaf area index and forest light conditions are essential to calibrate remotely-sensed information based on airborne and satellite data (Rich 1990, Wang et al. 2004).

\section{(1) Consiglio per la Ricerca e la} Sperimentazione in Agricoltura - Centro di Ricerca per la Selvicoltura, v. S. Margherita 80, I-52100 Arezzo (Italy); (2) Department for Innovation in Biological, Agro-Food, and Forestry systems, University of Tuscia, v. San Camillo de Lellis, I-01100 Viterbo (Italy)

(a), Francesco Chianucci

(francesco.chianucci@entecra.it)

Received: Sep 13, 2012 - Accepted: Nov 13, 2012

Citation: Chianucci F, Cutini A, 2012. Digital hemispherical photography for estimating forest canopy properties: current controversies and opportunities. iForest 5 : 290-295 [online 2012-12-17] URL:

http://www.sisef.it/iforest/contents? id=ifor $0775-005$

Communicated by: Roberto Tognetti
However, direct measurements of forest canopy are particularly challenging to obtain, owing to inherent difficulties in making direct measurements of forest, high levels of spatial and temporal variability, and difficulty of generalizing local measurements to the landscape scale (Chen \& Cihlar 1995, Chen et al. 1997, Macfarlane et al. 2007b).

Harvesting of trees for direct measurements in forest is labor intensive, destructive, time and money consuming, and can not be applied to large areas (Chen et al. 1997). Alternative and less destructive methods based on tree allometry and litterfall have been developed in order to measure forest canopy properties. Nevertheless, even these methods are labor intensive, time-consuming and not error-free because of their site- and species-dependency (Breda 2003). By contrast, remotely sensed vegetation indexes have novel potential but still need cross calibration by means of ground-based observations (Wang et al. 2004). As a consequence, indirect measures of forest canopy properties using ground-based instruments have long been implemented, as documented by the rich literature (i.e., Chen et al. 1997, Cutini et al. 1998, Breda 2003, Jonckheere et al. 2004, Macfarlane et al. 2007b).

Indirect methods enable estimation of forest canopy properties by measurements of the radiation transmission through the canopy, making use of the radiative transfer theory (Ross 1981). However, indirect methods, including the LAI-2000 plant canopy analyzer (Li-Cor, Lincoln, Nebraska) and AccuPAR Ceptometer (Decagon Devices, Pullman, WA), two of the most commonly used devices, are hindered by the complexity of forest canopy architecture (Chen et al. 1997) and the high-cost of the instruments (Macfarlane et al. 2007c).

Since the first approach provided by Evans \& Coombe (1959), hemispherical photography (also known as fish-eye photography) has long been used for the indirect optical measurement of forest canopy. However, because of significant obstacles involving film cameras (i.e., lack of software, time-consuming acquisition and processing procedures), film hemispherical photography has been progressively forsaken (Breda 2003). Advances in digital photographic technology have led to renewal of interest in photographic methods for indirectly quantifying forest canopy. So far, hemispherical photography is the widely used of several photographic techniques. Fish-eye photography enables characterization of forest canopy by means of photographs taken looking upward (or, in some cases, looking downward) through an extreme wide-angle lens (Jonckheere et al. 2004). The method has many advantages over the other indirect methods. It is rapid, inexpensive and readily available; hemispherical image provides a permanent record of the geometry distribution of gap fraction, which is generally used to calculate forest light regimes and canopy properties such as canopy openness, leaf area index, leaf angle distribution. Hence, hemispherical photography can greatly expands the number of the canopy properties that are possible to estimate, as compared with the other indirect methods.

In spite of the recent improvement in digital photography, significant obstacles to the adoption of digital hemispherical photography still remain; accurate and meaningful estimates of forest canopy properties with digital hemispherical photography are hindered by different critical steps, regarding image acquisition and software processing; thus, adequate field collection and image processing procedure is required to achieve the standard of an ideal device (Jonckheere et al. 2004).

The purpose of this contribution is to briefly introduce some of the major drawbacks of the digital hemispherical photography method. Given that different controversies of digital hemispherical photography have been usually treated separately, this contribution is aimed to: (i) provide a basic foreground of digital hemispherical photography, in order to outline strengths and weaknesses of the method; (ii) to give an update framework of the main procedure recently proposed to overcome the technical problems of digital hemispherical photography; (iii) to provide an reliable field measurement and images processing protocol for canopy description and analysis, particularly regarding sampling strategy. 


\section{Foreground to Digital Hemispherical Photography}

The first hemispherical lens was developed by Hill (1924), to study cloud formation. The first approach to fish-eye photography in forestry was then provided by Evans \& Coombe (1959), which used hemispherical photography to describe the light environment under forest canopy. Anderson (1964, 1971) used fish-eye photography to calculate the direct and scattered components of solar radiation from visible sky directions. Subsequently, film hemispherical photography has been used for a long time to estimate forest canopy properties (Bonhomme et al. 1974, Anderson 1981, Chan et al. 1986 Wang \& Miller 1987). However, technical and theoretical obstacles involving many time consuming steps have progressively prevented the wide spread adoption of film hemispherical photography (Breda 2003, Macfarlane et al. 2007c).

More recently, advances in digital photographic technology and image processing software have led to a renewal of interest in digital hemispherical photography for indirect quantification of forest canopy properties (Breda 2003, Macfarlane et al. 2007c, Jarčuška et al. 2010). Digital cameras have greatly simplified the process of image capture and processing, when compared with film cameras (Macfarlane 2011). In addition, over the last few years, numerous commercial software packages, as well as freeware programs for canopy analysis, have been developed (Frazer et al. 1999, Jonckheere et al. 2005, Jarčuška 2008). Recent studies confirmed the accuracy of digital hemispherical photography in estimating forest canopy properties (Englund et al. 2000, Jonckheere et al. 2005, Leblanc et al. 2005, Macfarlane et al. 2007a, Ryu et al. 2010a). Moreover, new photographic techniques have been tested recently, confirming the high potentiality of digital photography (Macfarlane et al. 2007b, Ryu et al. 2010b, Chianucci \& Cutini 2013).

\section{Theoretical background}

Hemispherical photography is a method that measures the gap fraction at multiple zenith angles. Gap fraction is computed by applying the Beer-Lambert law (eqn. 1):

$$
P(\theta)=\exp \left(-\frac{G(\theta) L A I}{\cos (\theta)}\right)
$$

where $L A I$ is the leaf area index, $\theta$ is the zenith angle of view, $G(\theta)$ is named G-function and corresponds to the fraction of foliage projected on the plane normal to the zenith direction. In theory, by measuring the gap fraction at multiple zenith angles it is possible to simultaneously determine both LAI and the foliage angle distribution function (Macfarlane et al. 2007b). Forest light environment was also derived from gap fraction.

The method makes the following assumptions:

- Leaves are randomly distributed within the canopy;

- Individual leaf size is small compared with the canopy and thereby with the sensor field of view;

- Foliage is black, namely it do not transmit light;

- Leaves are azimuthally randomly oriented.

\section{Current controversies and corrective strategies}

\section{Photographic exposure}

Photographic exposure affects the magnitude of the canopy gap fraction (Zhang et al. 2005). The importance of exposure control is well documented, since automatic exposure has been demonstrated to prevent accurate and reliable estimates of the gap fraction (Chen et al. 1991, Macfarlane et al. 2000, Zhang et al. 2005). Images taken with automatic exposure underestimates gap fraction in open canopies, while overestimates gap fraction in medium-high density canopies (Zhang et al. 2005); as a consequence, exposure needs to be manually set.

The optimum exposure for hemispherical photography would be the one which makes the sky appear as white as possible, providing in the meantime the best contrast between canopy and sky (Chen et al. 1991). Adequate exposure can be approximately determined in two steps:

- reference exposure is measured in a clearing (open sky), with aperture set to provide adequate depth of field;

- subsequently, exposure is set to overexpose image (generally by 1-3 stops of the shutter speed) relative to the open sky reference (Macfarlane et al. 2000, Zhang et al. 2005, Macfarlane et al. 2007c), with the aperture unchanged. This exposure setting makes the sky appears white, providing satisfactory contrast between canopy and sky, and is not influenced by the stand density (Zhang et al. 2005).

\section{Gamma function}

Unlike film cameras, image sensors in digital cameras have the advantage of respond linearly to light (Zhang et al. 2005). However, in order to simulate the non-linear behavior of the human eye, the in-camera software applies a logarithmic transformation by means of gamma function (Cescatti 2007). The gamma function describes the relation between actual light intensity during photography and the resulting brightness value of the pixel (Wagner 1998). A gamma value of 1.0 denotes an image that accurately reproduces actual light intensity (Macfarlane et al. 2007c). Digital cameras typically have gam- ma values between 2.0 - 2.5. The main effect of this correction is to lighten the midtones, thus resulting in worse estimate of canopy light transmittance (Cescatti 2007).

Some studies found that gamma correction strongly affects forest canopy properties estimates in both film and digital cameras (Wagner 1998, Leblanc et al. 2005, Macfarlane et al. 2007c); consequently, back-correcting to 1 the gamma function of the images is recommended.

\section{Pixel classification}

The optimal light intensity (brightness value) from a digital color or grey levels image is generally used as threshold value to distinguish pixels belonging to sky or canopy, thus producing a binary image (Wagner 1998, Jonckheere et al. 2004, Jonckheere et al. 2005, Cescatti 2007). Some authors suggested using the blue channel instead of the grey levels of the RGB image, because the foliage elements have a much lower reflectivity and transmittance in the blue region of the visible electromagnetic spectrum (Leblanc et al. 2005, Zhang et al. 2005, Macfarlane 2011).

Previously, pixel classification was performed manually. Some software package such as GLA (Gap Light Analyzer - Frazer et al. 1999) still employs interactive manual thresholding. However, some studies pointed out that manual thresholding could be a relevant source of error due to its subjectivity (Rich 1990, Jonckheere et al. 2004, Cescatti 2007, Jarčuška et al. 2010). As a consequence, different automatic, objective, operator-independent thresholding methods have been proposed to replace manual thresholding (Ishida 2004. Jonckheere et al. 2005, Nobis \& Hunziker 2005, Macfarlane 2011), while commercial software packages (i.e., Winscanopy) typically have developed automatic pixel classification algorithms (Macfarlane 2011).

A detailed analysis of the different classification methods falls out of the scope of this contribution (for a more complete description, see Wagner \& Hagemeier 2006, Macfarlane 2011). However, Macfarlane et al. (2007c) noted that correcting images for the camera's gamma function and correcting the gap fraction distribution for foliage clumping are more important on leaf area index derived from digital hemispherical photography than the classification method chosen. In addition, Macfarlane (2011) even found that none of the more complicated classification methods available for image processing (also from remotely-sensed imagery classification procedures) yielded results that greatly differed from a simple global binary threshold classification.

\section{Leaf area index estimates}

Three main sources of discrepancy are 
commonly recognized when digital hemispherical photography is used to estimate forest leaf area index.

(a) Digital hemispherical photography estimates a plant area index, rather than actual leaf area index, due to the contribution of woody elements (Breda 2003). Deciduous forests allow the estimation of woody area index from optical sensors, which can be estimated from gap fraction during leafless (Cutini et al. 1998, Leblanc 2008). For evergreen broadleaved and coniferous species, the woody material could be estimated from destructive sampling (Leblanc 2008), or from tabled woody to total area ratio (Chen et al. 1997)

(b) Another source of discrepancy is the clumping of foliage (Breda 2003, Macfarlane et al. 2007c). Foliage clumping $(\Omega)$ strongly affect the canopy gap fraction, according to the Beer-Lambert law (eqn. 2, as modified by Nilson 1971):

$$
P(\theta)=\exp \left(-\frac{G(\theta) \Omega L A I}{\cos (\theta)}\right)
$$

To overcome the limit of a non-random distribution of foliage within the canopy, some commercial software for hemispherical image analysis (i.e., Winscanopy) calculates clumping indexes from an analysis of the gap size distribution (Chen \& Cihlar 1995) or from the gap fraction distribution of a number of azimuth segments for each annulus of the hemisphere (Lang \& Xiang 1986, Van Gardingen et al. 1999), or by combining these two approaches (Leblanc et al. 2005).

Van Gardingen et al. (1999) demonstrated that correcting for foliage clumping can reduce the underestimation of up to $15 \%$, compared with conventional analysis of hemispherical photography, which can results in an underestimate of $50 \%$ of the leaf area in dex derived from harvesting. Another advantage of fish-eye photography is that the instrument enables assessment of both within and between crowns clumping effects, which results in greater accuracy in LAI retrieval in dense canopies, when compared with LAI-2000 PCA (Chianucci \& Cutini 2013).

(c) Even though an apparent advantage of fisheye photography is that LAI and the extinction coefficient $(k)$ are simultaneously estimated [G-function is related to extinction coefficient by $G(\theta)=k \cdot \cos (\theta)]$, previous studies found that the foliage angle distribution calculated from hemispherical photography appeared sensitive to canopy structure (Chen \& Black 1991, Macfarlane et al. 2007a). As such, the foliage angle distribution calculated from fish-eye images should be treated with caution. To overcome this limit, an alternative is measuring the gap fraction at a single zenith angle of $\theta=57.5^{\circ}$ given that the extinction coefficient at this angle was largely independent of the foliage angle distribution (Bonhomme \& Chartier 1972). Some software packages allow the 57.5 degree analysis of fish-eye images (i.e., Winscanopy and CAN-EYE).

\section{Protocol for image acquisition and hemispherical software image analysis}

In order to provide clear and concise suggestions to get the most out of using digital cameras for forest canopy properties estimation, an hypothetical application of digital hemispherical photography is illustrated, with an example of the compact camera Nikon CoolPix 4500, equipped with the FCE8 fish-eye lens converter, and the Winscanopy software. Camera setup and software analysis was set according to Macfarlane et al. $(2007 \mathrm{c})$. The reason for choosing a compact camera is motivated mainly because the Nikon CoolPix models have been very popular in this field, and the performance of these cameras, as well as other compact camera models, have been deeply investigated. For instance, Frazer et al. (2001) compared film photography with the 2.1 Megapixel Coolpix 950, Inoue et al. (2004) compared the effect of quality and image size in two different Coolpix models (990 vs. 900), Leblanc et al. (2005) used both Coolpix 990 and 5000 in boreal forests, Englund et al. (2000) tested the effect of image quality using the Coolpix 950. These researchers found that little or no differences exists between TIFF and JPEG images from the same camera, but that image size can influence canopy properties estimates.

Recently, DSLR (Digital Single Lens Reflex) cameras have become much more affordable and their resolution has greatly increased (Pekin \& Macfarlane 2009), but thorough appraisals using DSLR cameras are still poorly documented; hence, generalization over canopy measurement procedures using DSLR cameras can not be achieved so far. However, we refers to the work of Pekin \& Macfarlane (2009) for a detailed analysis of the effect of quality, image size, file format, ISO in both Coolpix 4500 and DSLR Nikon D80.

\section{Sampling strategy}

Sampling strategy is a key issue when performing ground measurements that need to be representative of the whole canopy (Weiss et al. 2004). Number of images and spatial location of shots define the sampling strategy. Canopy and vegetation type, spatial variability, plot area, sensor angle of view and distance to the edge of the stand can greatly influence the accuracy of sampling design (Chason et al. 1991).

It is best to consider a sampling protocol designed for the canopy type which is being measured. Canopy height is the first factor which should be considered. As a rule-ofthumb, the distance between the sensor and the nearest leaf should be at least four times the width of the leaf. As a consequence, the use of upward pointing fish-eye images in short canopies such as grassland and agricultural crops should be carefully evaluated (Leblanc 2008). The distance between the lens and the canopy may be too short, and the resulting canopy covered by the field of view of the camera may be not representative of the spatial distribution of the canopy (Liu \& Pattey 2010), When this situation occurs, the use of downward looking camera orientation comes as a reliable and practical alternative for agricultural crops and grassland (Demarez et al. 2008, Garrigues et al. 2008, Liu \& Pattey 2010). Downward pointing camera can also be used to separate understory vegetation and top canopy vegetation in a forest stand.

Canopy spatial variability is a major factor affecting sampling strategies. For closed and randomly distributed canopies, a grid of sample points is usually a suitable strategy (Law et al. 2001), even though predetermined sample location may require several adjustments, in that the presence of leaves immediately above the sensor may block the entire view at low zenith angles. By contrast, Leblanc et al. (2002) proposed the sampling along a $70 \mathrm{~m}$ transects over boreal and temperate forests, with measurements every 10 $\mathrm{m}$.

In the case of regular tree distributions, e.g., plantations of tree in evenly spaced rows, the adoption of a crisscross array scheme is recommended to ensure sampling under trees, thus avoiding bias from inter-row gaps sampling (Chen et al. 1997); the sample distance should be proportional to the range of distances between rows (Weiss et al. 2004).

Accurate samplings in open and heterogeneous canopies are more challenging to obtain. Gap fraction is greatly influenced by clumping, especially in heterogeneous canopies (see eqn. 2). Moreover, clumping occurs at different scales, from shoot level (within crown) to stand level (between crowns). This multiscale nature makes it hard to quantify foliage clumping (Ryu et al. 2010a).

Irrespective of the method used to estimate gap fraction, in most applications gap fraction is given only in term of zenith angle, since an assumption of azimuthal symmetry is generally used (Van Gardingen et al. 1999, Leblanc 2008). This assumption implies that such standard techniques should be limited to homogeneous canopies. It is well known that conifer needles are not randomly arranged in space, and radiation penetration models assuming homogeneous canopy will underestimate the transmittance of a conifer canopy. Hemispherical photography enables assessment of both within and between 
Tab. 1 - Main characteristics of the most diffuse hemispherical image processing software packages.

\begin{tabular}{|c|c|c|c|c|c|}
\hline Software & Company & $\begin{array}{l}\text { Pixel } \\
\text { classification }\end{array}$ & Availability & LAI methods & Clumping index \\
\hline Winscanopy & $\begin{array}{l}\text { Regent Instruments } \\
\text { Inc., Quebec, Canada }\end{array}$ & $\begin{array}{l}\text { Automatic and } \\
\text { interactive } \\
\text { (manual) }\end{array}$ & Commercial & $\begin{array}{l}57.5^{\circ} \text { (Bonhomme \& Chartier 1972) } \\
\text { LAI } 2000 \text { (Miller 1967) } \\
\text { Generalized LAI } 2000 \\
\text { Ellipsoidal (Norman \& Campbell 1989) }\end{array}$ & $\begin{array}{l}\text { Chen \& Cihlar (1995) } \\
\text { Lang \& Xiang (see Van } \\
\text { Gardingen et al. 1999) } \\
\text { Hybrid (see Leblanc et al. } \\
\text { 2005) }\end{array}$ \\
\hline GLA & $\begin{array}{l}\text { Cary Institute of } \\
\text { Ecosystems studies, } \\
\text { Millbrook, New York, } \\
\text { US }\end{array}$ & Manual & Free & LAI 2000 (Miller 1967) & No \\
\hline CAN-EYE & $\begin{array}{l}\text { INRA (French Natio- } \\
\text { nal Institute of Agro- } \\
\text { nomical research) }\end{array}$ & $\begin{array}{l}\text { Automatic and } \\
\text { interactive } \\
\text { (manual) }\end{array}$ & Free & $\begin{array}{l}57.5^{\circ} \text { (Bonhomme \& Chartier 1972) } \\
\text { LAI } 2000 \text { (Miller 1967) }\end{array}$ & $\begin{array}{r}\text { Lang \& Xiang (see Van } \\
\text { Gardingen et al. 1999) }\end{array}$ \\
\hline HemiView & $\begin{array}{l}\text { Delta-T Device Ltd. } \\
\text { Cambridge, UK }\end{array}$ & Manual & Commercial & LAI 2000 (Miller 1967) & No \\
\hline Hemisfer & $\begin{array}{l}\text { WLS Swiss Federal } \\
\text { Institute for Forest, } \\
\text { Snow and Landscape } \\
\text { Research }\end{array}$ & $\begin{array}{l}\text { Automatic and } \\
\text { interactive } \\
\text { (manual) }\end{array}$ & Commercial & $\begin{array}{l}57.5^{\circ} \text { (Bonhomme \& Chartier 1972) } \\
\text { LAI } 2000 \text { (Miller 1967) } \\
\text { Generalized LAI } 2000 \\
\text { Ellipsoidal (Norman \& Campbell 1989) }\end{array}$ & $\begin{array}{l}\text { Chen \& Cihlar (1995) } \\
\text { Lang \& Xiang (see Van } \\
\text { Gardingen et al. 1999) }\end{array}$ \\
\hline
\end{tabular}

crowns clumping (for more details, see the section "Leaf area index estimates". As such, the incorporation of clumping is strongly recommended, when available from software outputs (Tab. 1).

Again, heterogeneous canopies require more repetitions (images) than homogeneous canopies to achieve good spatial sampling. Image-processing software also allows to mask some part of the hemisphere, in order to reduce the field of view, which may improve spatial representation in heterogeneous canopies, i.e., to include dense and sparse regions of a heterogeneous canopy in separate images.

The masking procedure could also be used in mixed forests, in order to sample clusters of different species in different images. Masking can also be used to prevent some undesired part of the image from being analyzed (i.e., sun glint, operator, etc).

As previously outlined, use of downward pointing camera enables analysis of understory, and even allows separating this component from top of canopy elements. In the case of taller understory, Rich et al. (1999) suggested using tall-folding monopod with self-leveling mount set-up to sample top of canopy, or, alternatively, using a ladder. Use of a ladder also enable measuring canopy at different heights, which could be useful in tropical wet forests.

Other sampling difficulties arise from measurement on single trees, because indirect methods are poorly suitable for single plants (Cutini \& Varallo 2006). However, Hemiview software proposes specific options for measurements on single trees (Rich et al. 1999). The LAI-2000 user's manual proposes similar suggestions, which can also be suited to hemispherical photography.

Specific precautions should be adopted for slope, such as holding the lens normal to the ground; e.g., self-leveling tripod is provided with Winscanopy equipment. Some authors even suggested corrective methods to introduce slope effect in the analysis (Walter \& Torquebiau 2000, Schleppi et al. 2007).

\section{Image acquisition}

Hemispherical images should be collected in summer, under fully developed canopy conditions, and under uniform overcast sky, or alternatively close to sunrise or sunset (Leblanc et al. 2005); both these sky conditions enable a perfect diffuse sky, thus avoiding the interference of direct sunlight, which can cause errors of up to $50 \%$ (Welles \& Norman 1991).

Images should be collected as fine quality and at maximum resolution JPEG, with the lens set to $F 1$, which enables circular images. Lens set to F2 enables full-frame fisheye image instead of circular image, with the former having a better resolution than the circular format. However, only recent releases of Winscanopy software (since 2006a version) have implemented analysis of fullframe image; so far, canopy analysis has been usually performed only on circular images (Macfarlane et al. 2007b). Camera must be aligned to magnetic north and pointed upward by means of a self-leveling tripod. The aperture must be set to minimum (5.3) and, with the camera in aperture-priority (A) mode, the exposure must be recorded in an adjacent clearing. Subsequently, the mode must be changed to manual (M) and the shutter speed must be lowered by two stops in comparison to the exposure metered in the clearing (Zhang et al. 2005). Exposure should be measured regularly beneath the canopy using a spot light meter, in order to check possible changes in sky conditions during image acquisition (Macfarlane et al. 2007c).

Different exposures can be promptly collected by setting exposure bracketing, which automatically adjust the shutter speed from the starting exposure, which is set by the operator (i.e., the open sky reference). On the other hand, digital cameras which can save image files in RAW format, such as DSLR allows varying the exposure after image acquisition.

\section{Software image analysis}

Gamma function of the images needs backcorrection to 1 prior to hemispherical software image analysis. Given that Nikon CoolPix 4500 has a gamma function of approximately 2.2 (Leblanc et al. 2005), the original images must be adjusted with the gamma correction set to $0.45(1 / 2.2)$, using a standard image manipulation program such as Irfanview (Macfarlane et al. 2007b).

In the blue band of the electromagnetic spectrum, the foliage appears darker than in the other bands, thus minimizing the interference of multiple scattering in the canopy and chromatic aberration (Zhang et al. 2005). In addition, in diffuse sky conditions, the sky is saturated in the blue band, and thus appears white in 8-bit blue channel (Leblanc 2008). As such, the blue channel of the images should be used in the canopy analysis to achieve optimal brightness value (thresholding). Image must be sharpened (medium), to enhance the contrast between sky and canopy, and then analyzed using 
hemispherical image analysis software. Winscanopy enables automatic pixel classification of the images, thus avoiding human input.

In addition, Wincanopy enables correction for clumping foliage, which can significantly reduce the underestimation of leaf area index in clumped canopies (Lang \& Xiang 1986, Van Gardingen et al. 1999, Jonckheere et al. 2004, Chianucci \& Cutini 2013).

A zenithal angle range of $0-70^{\circ}$ and 8 azimuth segments should be adequate for the image analysis (Macfarlane et al. 2007c).

\section{Comparison of software packages}

The more popular commercial software packages are Winscanopy and Hemiview. Their standard systems include a digital camera, a calibrated fish-eye lens and a selfleveling tripod. Free software packages are available for hemispherical image analysis such as GLA (Gap Light Analyzer - Frazer et al. 1999) and CAN-EYE.

Most of the scientific studies concerning hemispherical photography use method based on the determination of optimal threshold (Hemiview, GLA, Winscanopy). Moreover, most of these studies focused on forest canopies (Demarez et al. 2008). CANEYE is also widely used in agricultural environments, because of its ability to perform different pixel classification procedures, as compared with thresholding method, thereby allowing analysis of downward-looking images (Demarez et al. 2008). Tab. 1 lists the main characteristics of some of the most widely used software packages.

\section{Conclusive considerations}

Despite uncertainties due to image acquisition and processing steps, digital photography holds great promise for estimating forest canopy properties, on account of its speed, ready availability and low-cost, which enables widespread use of the method. Photography even shows good potential to replace other indirect methods, due to its ability to provide simultaneously several parameters characterizing solar radiation and forest canopy properties (Chen et al. 1997). In addition, unlike other methods, hemispherical photograph can be interpreted as a map of canopy openings (or, on the contrary, of canopy closure) relative to the locations from which image is taken, which can be inspected to provide insight into heterogeneity within a canopy and to compare different canopies at different sites (Rich et al. 1999). Last, but not least, digital photography enables widespread use of the method. Aside from scientific purposes, photography can be suitably applied for management and monitoring issues, i.e., routine canopy properties estimation.

Recent advances in digital photographic equipments such as higher resolution came- ras and better quality lenses, combined with robust and efficient image processing routines and software packages, are bringing digital photography to a mature stage, where the field techniques and image processing steps are no longer significant obstacle limiting its application (Macfarlane 2011).

\section{Acknowledgements}

This research was supported by RI.SELV.ITALIA Research Program 3.1 "Silviculture, productivity and conservation of forest ecosystems" research project and by the Research Program D.M. 19477/7301/08 - "Maintenance of collections, databases, and other activities of public interest" funded by the Italian Ministry of Agriculture and Forest Policies.

\section{References}

Anderson MC (1964). Studies of the woodland light climate I. The photographic computation of light condition. Journal of Ecology 52: 27-41. doi: $10.2307 / 2257780$

Anderson MC (1971). Radiation and crop structure. In: "Plant Photosynthetic Production. Manual of Methods" (Sestak Z, Catsky J, Jarvis PG eds). Junk, the Hague, The Netherlands, pp. 77-90.

Anderson MC (1981). The geometry of leaf distribution in some south-eastern Australian forests. Agricultural Meteorology 25:195-205. - doi: 10.1016/0002-1571(81)90072-8

Bonhomme R, Chartier P (1972). The interpretation and automatical measurement of hemispherical photographs to obtain sunlit foliage area and gap frequency. Israel Journal Agricultural Research 22: 53-61.

Bonhomme R, Varlet-Grancher C, Chartier M (1974). The use of hemispherical photographs for determining the leaf area index of young crops. Photosynthetica 8: 299-301.

Breda NJ (2003). Ground-based measurements of leaf area index: a review of methods, instruments and current controversies. Journal of Experimental Botany 54 (392): 2403-2417. - doi: $10.1093 / \mathrm{jxb} / \mathrm{erg} 263$

Cescatti A (2007). Indirect estimates of canopy gap fraction based on the linear conversion of hemispherical photographs. Agricultural and Forest Meteorology 143 (1-2): 1-12. - doi: 10.1016/j.agrformet.2006.04.009

Chan SS, McCreight RW, Walstad JD, Spies TA (1986). Evaluating forest vegetative cover with computerized analysis of fisheye photographs. Forest Science 32: 1085-1091.

Chason JW, Baldocchi DD, Huston MA (1991). A comparison of direct and indirect methods for estimating forest canopy leaf area. Agricultural and Forest Meteorology 57 (1-3): 107-128. - doi: 10.1016/0168-1923(91)90081-Z

Chen J, Black T (1991). Measuring leaf area index of plant canopies with branch architecture. Agricultural and Forest Meteorology 57 (1-3): 112. - doi: 10.1016/0168-1923(91)90074-Z

Chen J, Black T, Adams R (1991). Evaluation of hemispherical photography for determining plant area index and geometry of a forest stand. Agricultural and Forest Meteorology 56 (1-2): 129143. - doi: 10.1016/0168-1923(91)90108-3

Chen J, Cihlar J (1995). Quantifying the effect of canopy architecture on optical measurements of leaf area index using two gap size analysis methods. IEEE Transactions on Geoscience and Remote Sensing 33 (3): 777-787. - doi: 10.1109/ 36.387593

Chen JM, Rich PM, Gower ST, Norman JM, Plummer S (1997). Leaf area index of boreal forests: theory, techniques, and measurements. Journal of Geophysical Research 102 (D24): 29429. - doi: 10.1029/97JD01107

Chianucci F, Cutini A (2013). Estimation of canopy properties in deciduous forests with digital hemispherical and cover photography. Agricultural and Forest Meteorology 168: 130-139. doi: 10.1016/j.agrformet.2012.09.002

Cutini A (2003). Litterfall and leaf area index in the CONECOFOR permanent monitoring plots. Journal of Limnology 61: 62-68.

Cutini A, Matteucci G, Mugnozza GS (1998). Estimation of leaf area index with the Li-Cor LAI 2000 in deciduous forests. Forest Ecology and Management 105 (1-3): 55-65. - doi: 10.1016/ S0378-1127(97)00269-7

Cutini A, Varallo A (2006). Estimation of foliage characteristics of isolated trees with the Plant Canopy Analyzer LAI-2000. Current Trends in Ecology 1: 49-56.

Demarez V, Duthoit S, Baret F, Weiss M, Dedieu G (2008). Estimation of leaf area and clumping indexes of crops with hemispherical photographs. Agricultural and Forest Meteorology 148 (4): 644-655. - doi: 10.1016/j.agrformet.2007. 11.015

Englund SR, O’Brien JJ, Clark DB (2000). Evaluation of digital and film hemispherical photography for predicting understorey light in a Bornean tropical rain forest. Agricultural and Forest Meteorology 97: 129-139.

Evans GD, Coombe DE (1959). Hemispherical and woodland canopy photography and the light climate. Journal of Ecology 47: 103-113. - doi: 10.2307/2257250

Frazer GW, Canham CD, Lertzman K (1999). Gap light analyzer (GLA). Version 2.0. Imaging software to extract canopy structure and gap light transmission indices from true-color fisheye photographs: user's manual and program documentation. Simon Fraser University, Burnaby, BC, Canada, pp.36.

Frazer GW, Fournier RA, Trofymow J, Hall RJ (2001). A comparison of digital and film fisheye photography for analysis of forest canopy structure and gap light transmission. Agricultural and Forest Meteorology 109 (4): 249-263. - doi: 10.1016/S0168-1923(01)00274-X

Garrigues S, Shabanov N, Swanson K, Morisette J, Baret F, Myneni R (2008). Intercomparison and sensitivity analysis of Leaf Area Index retrievals from LAI-2000, AccuPAR, and digital hemispherical photography over croplands. Agricultural and Forest Meteorology 148 (8-9): 1193 - 
1209. - doi: 10.1016/j.agrformet.2008.02.014 Hill R (1924). A lens for whole sky photographs. Quarterly Journal of the Royal Meteorological Society 50: 227-235. - doi: 10.1002/qj.497050 21110

Inoue A, Yamamoto $\mathrm{K}$, Mizoue N, Kawahara Y (2004). Effects of image quality, size and camera type on forest light environment estimates using digital hemispherical photography. Agricultural and Forest Meteorology 126 (1-2): 89-97. - doi: 10.1016/j.agrformet.2004.06.002

Ishida M (2004). Automatic thresholding for digital hemispherical photography. Canadian Journal of Forest Reasearch 34: 2208-2216. doi: $10.1139 / \mathrm{x} 04-103$

Jarčuška B (2008). Methodological overview to hemispherical photography, demonstrated on an example of the software GLA. Folia Oecologica 35: 66-69.

Jarčuška B, Kucbel S, Jaloviar P (2010). Comparison of output results from two programmes for hemispherical image analysis: Gap Light Analyser and WinScanopy. Journal of Forest Science 56 (4): 147-153.

Jonckheere I, Fleck S, Nackaerts K, Muys B, Coppin P, Weiss M, Baret F (2004). Review of methods for in situ leaf area index determination: Part I. Theories, sensors and hemispherical photography. Agricultural and Forest Meteorology 121 (1-2): 19-35. - doi: 10.1016/j.agrformet.2003. 08.027

Jonckheere I, Nackaerts K, Muys B, Coppin P (2005). Assessment of automatic gap fraction estimation of forests from digital hemispherical photography. Agricultural and Forest Meteorology 132 (1-2): 96-114. - doi: 10.1016/j.agrformet.2005.06.003

Lang ARG, Xiang Y (1986). Estimation of leaf area index from transmission of direct sunlight in discontinuous canopies. Agricultural and Forest Meteorology 37 (3): 229-243. - doi 10.1016/0168-1923(86)90033-X

Law B, Van Tuyl S, Cescatti A, Baldocchi D (2001). Estimation of leaf area index in opencanopy ponderosa pine forests at different successional stages and management regimes in Oregon. Agricultural and Forest Meteorology 108 (1): 1-14. - doi: 10.1016/S0168-1923(01) 00226-X

Leblanc SG (2008). DHP-TRACWin Manual. Version 1.03. Natural Resources Canada, SaintHubert, Quebec, Canada, pp. 29.

Leblanc SG, Chen JM, Fernandes R, Deering DW, Conley A (2005). Methodology comparison for canopy structure parameters extraction from digital hemispherical photography in boreal forests. Agricultural and Forest Meteorology 129 (3-4): 187-207. - doi: 10.1016/j.agrformet.2004 09.006

Leblanc SG, Fernandes R, Chen JM (2002). Recent advancements in optical field leaf area index, foliage heterogeneity, and foliage angular distribution measurements. In: Proceedings of "IGARSS 2002". Toronto (Canada) 24-28 June 2002.

Liu J, Pattey E (2010). Retrieval of leaf area index from top-of-canopy digital photography over agricultural crops. Agricultural and Forest Meteorology 150 (11): 1485-1490. - doi: 10.1016/j.agrformet.2010.08.002

Macfarlane C (2011). Classification method of mixed pixels does not affect canopy metrics from digital images of forest overstorey. Agricultural and Forest Meteorology 151 (7): 833-840. - doi: 10.1016/j.agrformet.2011.01.019

Macfarlane C, Coote M, White DA, Adams MA (2000). Photographic exposure affects indirect estimation of leaf area in plantations of Eucalyptus globulus Labill. Agricultural and Forest Meteorology 100 (2-3): 155-168. - doi: 10.1016/ S0168-1923(99)00139-2

Macfarlane C, Arndt SK, Livesley SJ, Edgar AC, White DA, Adams MA, Eamus D (2007a). Estimation of leaf area index in eucalypt forest with vertical foliage, using cover and fullframe fisheye photography. Forest Ecology and Management 242 (2-3): 756-763. - doi: 10.1016/j.foreco.2007.02.021

Macfarlane C, Grigg A, Evangelista C (2007b). Estimating forest leaf area using cover and fullframe fisheye photography: Thinking inside the circle. Agricultural and Forest Meteorology 146 (1-2): 1-12. - doi: 10.1016/j.agrformet.2007. 05.001

Macfarlane C, Hoffman M, Eamus D, Kerp N, Higginson S, Mcmurtrie R, Adams M (2007c). Estimation of leaf area index in eucalypt forest using digital photography. Agricultural and Forest Meteorology 143 (3-4): 176-188. - doi: 10.1016/j.agrformet.2006.10.013

Miller J (1967). A formula for average foliage density. Australian Journal of Botany 15: 141144. - doi: 10.1071/BT9670141

Nilson T (1971). A theoretical analysis of the frequency of gaps in plant stands. Agricultural Meteorology 8: 25-38. - doi: 10.1016/00021571(71) 90092-6

Nobis M, Hunziker U (2005). Automatic thresholding for hemispherical canopy-photographs based on edge detection. Agricultural and Forest Meteorology 128 (3-4): 243-250. - doi: 10.1016/j.agrformet.2004.10.002

Norman JM, Campbell GS (1989). Canopy structure. In: "Plant physiological ecology: field methods and instrumentation" (Pearcy RW, Ehleringer JR, Mooney HA, Rundel PW eds). Chapman and Hall, London, pp. 301-325.

Pekin B, Macfarlane C (2009). Measurement of crown cover and leaf area index using digital cover photography and its application to remote sensing. Remote Sensing 1 (4): 1298-1320. - doi: 10.3390/rs1041298

Rich PM (1990). Characterizing plant canopies with hemispherical photographs. Remote Sensing Reviews 5 (1): 13-29. - doi: 10.1080/ 02757259009532119

Rich PM, Wood J, Vieglais DA, Burek K, Webb N (1999). HemiView manual revision no. 2.1. Delta-T Devices, Ltd.

Ross J (1981). The radiation regime and architecture of plant stands. Junk, London, pp. 391.

Ryu Y, Nilson T, Kobayashi H, Sonnentag O,
Law BE, Baldocchi DD (2010a). On the correct estimation of effective leaf area index: does it reveal information on clumping effects? Agricultural and Forest Meteorology 150 (3): 463-472. doi: 10.1016/j.agrformet.2010.01.009

Ryu Y, Sonnentag O, Nilson T, Vargas R, Kobayashi H, Wenk R, Baldocchi DD (2010b). How to quantify tree leaf area index in an open savanna ecosystem: a multi-instrument and multi-model approach. Agricultural and Forest Meteorology 150 (1): 63-76. - doi: 10.1016/j.agrformet.2009. 08.007

Schleppi P, Conedera M, Sedivy I, Thimonier A (2007). Correcting non-linearity and slope effects in the estimation of the leaf area index of forests from hemispherical photographs. Agricultural and Forest Meteorology 144 (3-4): 236 242. - doi: 10.1016/j.agrformet.2007.02.004

Van Gardingen P, Jackson G, Hernandez-Daumas S, Russell G, Sharp L (1999). Leaf area index estimates obtained for clumped canopies using hemispherical photography. Agricultural and Forest Meteorology 94 (3-4): 243-257. - doi: 10.1016/S0168-1923(99)00018-0

Wagner S (1998). Calibration of grey values of hemispherical photographs for image analysis. Agricultural and Forest Meteorology 90 (1-2): 103-117. - doi: 10.1016/S0168-1923(97)000737

Wagner S, Hagemeier M (2006). Method of segmentation affects leaf inclination angle estimation in hemispherical photography. Agricultural and Forest Meteorology 139 (1-2): 12-24. - doi: 10.1016/j.agrformet.2006.05.008

Walter JMN, Torquebiau EF (2000). The computation of forest leaf area index on slope using fisheye sensors. Comptes Rendus de l'Académie des Sciences, Série III Sciences de la Vie, vol. 323, pp. 801-813.

Wang YS, Miller DR (1987). Calibration of the hemispherical photographic technique to measure leaf area index distributions in hardwood forests. Forest Science 33: 110-126.

Wang Y, Woodcock CE, Buermann W, Stenberg P, Voipio P, Smolander H, Häme T, Tian Y, Hu J, Knyazikhin Y, Myneni RB (2004). Evaluation of the MODIS LAI algorithm at a coniferous forest site in Finland. Remote Sensing of Environment 91 (1): 114-127. - doi: 10.1016/ j.rse.2004.02.007

Weiss M, Baret F, Smith GJ, Jonckheere I, Coppin $P$ (2004). Review of methods for in situ leaf area index (LAI) determination. Part II. Estimation of LAI, errors and sampling. Agricultural and Forest Meteorology 121 (1-2): 37-53. - doi: 10.1016/j.agrformet.2003.08.001

Welles JM, Norman JM (1991). Instrument for indirect measurement of canopy architecture. Agronomy Journal 83 (5): 818. - doi: 10.2134/agronj1991.00021962008300050009x

Zhang Y, Chen JM, Miller JR (2005). Determining digital hemispherical photograph exposure for leaf area index estimation. Agricultural and Forest Meteorology 133 (1-4): 166-181. - doi: 10.1016/j.agrformet.2005.09.009 